\title{
Navigating and Negotiating Ethnographies of Urban Hustle in Nairobi Slums
}

\begin{abstract}
This paper reflects on doing and writing ethnography on the urban margins, where uncertainty and provisionality mark the everyday city. The discussion is situated within a postcolonial approach to ethnographies of 'hustle' in Nairobi slums, critically reflecting on methodological choices made to facilitate the license to linger in intimate and interstitial spaces of neighbourhoods often closed off to visitors. The paper argues that while urban ethnography is foundational to post-colonial scholarship on African cities, it is also vexed with tensions between ethnographic experience of the provisional and uncertain lived reality in which ethnographers seek to embed themselves for periods of time, and the ethnographic representation that emerges in the form of ethnographic authorship. The paper engages with the methodological tactic to engage in waste work as an 'apprentice researcher'; and with the theoretical choice to deploy the very vocabularies and expressions of struggle of interlocutors living and working in the 'slums' of Nairobi.
\end{abstract}

\section{Key words: urban ethnography, hustle, Nairobi, slum urbanism}

\section{Situating the field}

7:30 a.m. Check my bag one more time: Note book, small pen, pocket knife, recorder, batteries, passport copy, crappy Nokia phone, bandana, 1,000 KES note in a hard-toreach pocket, 200 KES for transport and food for the day, a couple plastic bags to use for trash, water bottle, hand sanitizer... Put exact change for matatu in pocket, slip on boots. Walk for 30 minutes to town. Queue up at Iko Toilet next to Kenyan National Archives, likely the last easy to access toilet for the rest of the day. Give the lady 10 KES, she gives me a bit of toilet paper. If there is water and soap that is a good day. Get to the matatu stage across the street and wait for number 46 to fill up. Can take up to 20 minutes, maybe more. Window seat preferred, in second row. Once we get moving, I'm about 30 minutes from Mathare. Text one of the guys to say I'm on my way...Fieldwork day has started.

Nairobi's multi-directionality, movements and diversity are impossible to capture in a singular portrait. Navigating the city itself plays a significant role in negotiating the spatial and relational differences that are integral to methodological dilemmas and possibilities, including the first practical challenge regarding where to stay and how to get around. In this sense, urban ethnographic work complicates the boundaries between the doing and the writing. With each returning visit, the field site continues to expand temporally and spatially, stretching beyond the city itself as some research interlocutors become friends both in the field and virtually, and the ethnographer grapples with the ever-present political, and ethical dimensions of cultural representation (Clifford 1986), trust between researcher and research participant (Duneier 2000), and 
vulnerability of the observer (Behar 1996). A persisting predicament remains between managing the selfcritical acknowledgement that ethnographic writing is inherently contingent and always partial. At best we can attempt to capture fragments of lives, impressions, and experiences that may be shared and yet individually felt. Both as a method of research and a method of writing, ethnography becomes an on-going experiment in decoding and recoding (Clifford 1986) what we see, hear, and sense in the field. Ethnography is therefore at once inter-textual, affective, and a constant exercise in interpretation (Geertz 1973) of everyday practices and performances. Ethnography in and through a city also becomes not just a site of ephemeral and bounded 'fieldwork' but rather a place of continuous return, interrogation, and imagination. It is as much a process animating and recollecting place-based lived experiences as it is about representing multiple elsewheres, as ethnographic stories seek to connect individual experiences with wider historical and geographical contexts (Jeffrey and Dyson 2009). As such, the city becomes ethnographic text, and the ethnography moves with the city and through time.

The practice of urban ethnography is further complicated when the 'subjects' are on the margins, and the conditions of everyday life are highly uncertain and rooted in legacies of volatility and uneven development (Ferguson 2006; Cooper and Pratten 2015). As argued in the introduction of this special feature, conducting an ethnography on the urban margins challenges norms and mainstream narratives about what constitutes the city and city life. Makeshift cities are places of transience, porosity, mobility, and constant experimentation in the face of uncertainty (Simone 2004; Vasudevan 2014; Pieterse and Simone 2013). Studying and writing about life and work in an African city must contend with the unprecedented pace and shifting prisms of an urbanism that "we cannot yet 'determine' because it has not yet become or will never be definite" (Mbembe and Nuttall 2004: 349). An ethnographic approach therefore seems to be the only viable way to experience the "uncertainty and turbulence, instability and unpredictability, and rapid, chronic and multidirectional shifts" of everyday life on the margins of a city like Nairobi (ibid). Ethnography provides a humbling and albeit imperfect mode of "learning the city" (McFarlane 2010), coupled with the struggle to grasp let alone conceptualise the micro-geographies of everyday hustle (Thieme 2017) through empirical vignettes that say something about how the city works. But therein also lie significant epistemic dilemmas associated with what urban ethnographic work chooses to render visible, and how it does so, when the practice of "doing ethnography" (Crang and Cook 2007) is temporally and spatially contingent.

This paper aims to contribute to urban scholarship embedded in the challenges of constructing accounts of life at the margins (Lancione 2016). It reflects on the relationship between ethnography and makeshift urbanism following repeated ethnographic encounters in one of Nairobi's oldest and largest informal settlements ('slums'), Mathare. The paper outlines an ethnographic approach that moves with the city when its conceptual categories are fluid, mobile, provisional and marked with uncertainty (Cooper and Pratten 2015), and seeks to illustrate this through reflections from fieldwork conducted in Nairobi at multiple 
intervals over the last 10 years. ${ }^{1}$ My research has documented and conceptualised the forms of urban dwelling in a Nairobi slumscape through the lens of self-proclaimed 'hustlers' whose livelihood strategies are intimately tied to informal waste labour. While I have written elsewhere about the "hustle economy" of waste workers in Mathare (Thieme 2010; 2013; 2015; 2017) this is an opportunity to reflect critically on the process of doing an ethnography of the hustle in itself.

The paper is structured as follows: The first section outlines the challenges of defining the field conceptually and spatially. The second section discusses the role of self-reflexivity in ethnography to think through the implications and dilemmas associated with urban research involving people and places 'on the edge'. The third section reflects on what constitutes ethnographic data collection in the urban context through vignettes that show how ethnographic practice in itself further animates, rather than captures or solidifies, some of the 'difficult to pin down' and messy realities of urban life (Simone 2004). The fourth section focuses on the politics of knowledge production inherent in post-colonial writing. Overall, the paper argues that while urban ethnography is foundational to scholarship on African cities seeking to provide post-colonial and poststructuralist 'alternative visions' (Myers 2011) of urban ecologies, it is also vexed with tensions between ethnographic experience of the provisional and uncertain lived reality in which ethnographers seek to embed themselves for periods of time, and the ethnographic representation that emerges in the form of ethnographic authorship (Nagar 2006; Shepher-Hughes 2009). I reflect on this conundrum in two ways in my own work: first, methodologically by committing to engaging in waste work as an apprentice researcher in order to appreciate and document the craft involved in this often invisible and under-documented informal labour in the city; secondly, through my writing, by committing to drawing attention to the importance of theorizing from the very vocabularies and expressions of struggle of interlocutors living and working in the 'slums' of Nairobi.

\section{Finding the field}

A few weeks following my arrival in Nairobi for my PhD fieldwork in August 2009, my 'field site' became Mathare Valley, a low-income settlement approximately $7 \mathrm{~km}$ from Nairobi’s Central Business District. Despite the geographical distinction between where my family (husband and eight month old daughter) and I were living and my field site, the boundaries of my research were never clearly demarcated, spatially or temporally. There was no "village", no neatly bounded field site in the traditional ethnographic sense. In a way, fieldwork started (or resumed) when I walked out of the guest house my family and I rented from Professor Michieka, when my role and mode as mother had to transform into one of street smart researcher. Or perhaps it was when I stepped into my first matatu (fourteen seater informal mini-bus) of the day, when a kind of drive-by ethnographic montage provided the day's first bombardment of sensorial information that

\footnotetext{
${ }^{1}$ This includes a four week trip in 2005 an intensive 12-month research period during $\mathrm{PhD}$ fieldwork between 2009-2010, follow-up visits in 2011 and 2012, 2016, and 2017.
} 
would allow me to see and sense the "socio-technical systems" of this chaotic and dynamic city (Amin and Thrift 2016).

Conducting an urban ethnography is, in part, an exercise in negotiating and delimiting the 'field' in ways that challenge seemingly bounded (and countable) conceptual units of analysis such as the household, the village, and the homestead. This becomes a particularly acute methodological challenge when conducting research in urban informal settlements, where neighbourhoods, maps, census data and landmarks are contested, politicized, and often misrepresented by official statistics (Weru 2004). Throughout the course of my fieldwork, finding the 'field' required shifting temporal and spatial navigation, and often resembled a chameleon's game of adaptation and re-fashioning. As a European woman educated in the US and the UK, when in the company of other foreigners working for the large development agencies head-quartered in Nairobi, I could blend in with a certain expat community that shared similar university experiences and familiar cultural backgrounds. When I attended staff meetings at a local human rights organisation as an observing participant, I was invited into the NGO community focused on social justice for the urban poor. When I sought a quiet space with semi-reliable internet in the library of the British Institute of East Africa for some writing time, I was one of the multiple graduate students who had applied for a research permit to become a member of a research community where one's proficiency in Kiswahili and the amount of time spent 'in the field' seemed to grant more legitimacy than one's academic afiliation. Caught in the chaotic early morning hoard of pedestrians with a purpose in the Central Business District, I was swept up by the bustling motion of inner-city transience, one frustrated commuter amongst many trying to negotiate a moment to cross the streets with the impatient vehicles, deciding whether or not to hop on this matatu or the next.

This research has assumed continuous movement between different realities and spaces of the city, from the informal settlements underserved by mainstream urban services to the institutional actors in the city that purport to speak on behalf of the urban poor. The research at first involved a multi-sited ethnographic triangulation of different institutional and community actors' perceptions, discourses and experiences related to slum ecologies and economies. As such, the lines between the formal and the informal, the organizational and the interpersonal, the boardroom and the grassroots became increasingly blurred, as was the boundary between my personal lived experience as temporary Nairobi citizen and my identity as a researcher.

One muggy afternoon, I was sitting in a matatu jostling in and out of its lane on Juja Road, trying to defy the intense rush-hour traffic from Mathare to the City Centre an hour before sun-down. The percussive sounds of Swahili rap pushed the speakers to their limit, and as I made mental notes of the day's events, my tired gaze noticed a small sign pasted on the ragged interior wall above the driver's seat, "if the music is too loud, then you are too old!" These words reflect the unapologetic boldness of the matatu drivers and the whole matatu culture that so many people in Nairobi love to hate but depend on daily (Ference 2016). But at that moment it struck me that this also resonated with the narratives of the Mathare youth whose urban identities 
were wrapped up in a kind of "in your face" impudence that had become part of the performativity and vibrancy of the hustle economy. Stabilizing myself against another swerve and with the matatu's bass in my ears, I realized that the self-proclaimed hustlers whose lives I had been studying echoed the jolts of this matatu ride defying the perverse Nairobi traffic and formal rules: pragmatic, provocative, sometimes impatient and opportunistic. I have often wondered whether this moment was some kind of metaphor for fieldwork itself. The music was loud, the jerks and the smells and the traffic were sensorially intense, and somehow it felt like the city carried (or rather pushed) me around, rather than me moving around the city with any sort of control. I was exhausted and uncomfortable and it was simultaneously riveting and humbling.

In the early days of my fieldwork in Mathare, my goal was to reach a stage where my presence would no longer be strange or the source of undue fascination or amusement. And when I arrived at the base of the youth groups whose life histories, jobless corners and portfolio of small-scale businesses I studied, I took on the persona of a fellow youth urbanite, tapping into my tom-boyish mannerisms, greeting with fist bumps and speaking in my broken sheng and knowing that the day might involve spending hours idling with the guys if they were in between income generating activities, or putting on overalls and gum boots at dawn to work with one of the youth groups cleaning toilets or collecting garbage. And yet, despite Mathare's marginalized status within the city, in reality it is impossible to think of Mathare as a discrete settlement on the 'margins' of the mainstream city, or to assume that doing fieldwork only started when I arrived 'in the ghetto'.

\section{Navigating the field as vulnerable ethnographer}

There is an ethical and methodological question that underpins any urban ethnography, both as practice and as text. Conducting ethnographic research has always been about establishing connections between a researcher and individuals whose experiences are either under-recorded or misrepresented in some way. They are in this sense marginalized from mainstream knowledge production and representation. Behar (1996) has observed that in order to study the realities of individuals facing adverse life chances, it is paramount to consider two aspects of the research process: Firstly, it requires focusing on individual rather than solely cultural realities. Secondly, as researchers who tackle authorship, we can never truly do justice, in our later representations of "the data", to the actual interactions that occur during fieldwork between ourselves as researchers, and our interlocutors. Although Geertz (1988) famously argued that good ethnographic practice is person-specific and yet somehow not "personal", Behar's notion of "the vulnerable observer" has resonated in profound ways in my research over the years. Therefore I recognize that acknowledging and harnessing one's own subjectivity as a researcher becomes critical in urban ethnographic research concerned (and entangled) with life at the margins.

The depth of my insertion into the life worlds of the people who became key research protagonists (and in numerous cases, friends) was an underlying dilemma that informed my methodological choices and everyday 
encounters in the field. These choices then determined whether I self-identified as an academic alone, cataloguing observations, or whether I allowed my critical ethnographic faculties and activist penchant to inform the practice of fieldwork itself. Both have ethical implications and neither is apolitical in the end. Deliberately vocal about the role and dilemmas of the ethnographer, anthropologist Nancy Scheper-Hughes has provocatively advocated for a "militant anthropology" (1995), challenging the notion that contemporary ethnography could be "objectivist". She has argued for a "more frankly engaged" approach, and suggests that it seems impossible not to be "politically committed" if our work involves a pressing concern for the social justice issues that underpin our research contexts. Inspired by this but also aware of its implications, my political commitment has over the years informed my choices of data collected and the lens with which I have collected it.

Navigating access to any ethnographic research space is of course a familiar challenge, as negotiating positionality and establishing rapport with research participants always lies at the core of one's methodological anxieties and reflections. Participant observation and the experiential knowledge that comes with it is therefore often assumed to be the deepest form of inter-personal engagement with your research subject(s), involving getting close to people and making them feel comfortable enough with your presence that you can observe and record information about their lives (Bernard 2006). But in practice, I have found that there are layers of experiments and precursors leading up to the stage when the license to 'hang out' is finally acquired, and even then it always remains fragile, contingent, and can never be taken for granted.

Every moment in Nairobi has felt relevant to "the data", and my research mode had more to do with finding strategies to navigate different corners and pockets of the city, rather than securing interviews per se. For example, when I got off the matatu in Mathare, one of the first priorities upon arrival was to buy a chapatti (local flat bread) or a "cold drink" (soda). As a regular customer to many mamas selling vegetables, fruits, chai (tea) and chapattis, I had committed myself to small but routine acts of consumption that in turn set the stage for banter and over time, frank and unforced conversation. The temporality was significant here - if I were consuming a coke in a glass bottle, what could turn into a casual interview with an informal trader was bracketed by the time it took me to finish my drink and return the bottle to the kiosk. If I were waiting to meet someone, having my breakfast near the chapatti vendor gave me an excuse to linger and even sketch. Often my interlocutors would poke fun at my tendency to take incessant notes whenever I could. Eliza would jokingly ask, "is that "utafiti" (research) now?" I would explain that everything I saw helped me better understand the context of my research, "even when you try to teach me how to make a good round chapatti!"

As Danny Dorling states in his forward to Lisa McKenzie's account of Getting By in a British council estate, "We describe different worlds we live in to each other as those worlds move apart. More and more people try to span these worlds. Observation is no longer enough; immersion is no longer enough. As the gaps between our experiences grow it becomes even more necessary to hear largely first-hand, unadulterated 
accounts, the descriptions from the inside" (2015, xi). Dorling's statement is a valid critique of countless ethnographers (like me) who presume to cross over to unfamiliar life worlds, embed themselves in them, learn the language and the unstated codes that govern social relations and behaviours, and then, with appropriate humility but some authority, write about them later. In contrast, McKenzie is an author writing on class and inequality and life on a British council estate from the epistemic privilege of having experienced life on an estate. But for ethnographers who are not, themselves, originally from the neighbourhoods we write about, one of the methodological possibilities, particularly when the object of study includes particular kinds of (invisible or misunderstood) labour, is through a form of apprenticeship (Wacquant 2006). Apprenticeship comes with its own risk, but it can be a way to attain an embodied understanding of local codes, measures of risk, and rewards worth fighting for, or worth getting in trouble for. It offers a crucial window for understanding the cultural significance of concepts deployed in quotidian banter and expression, and becomes the epistemological channel through which meaningful conceptualisations of local realities may be understood.

My initial rapport with waste workers was built while participating in toilet cleaning jobs operated out of a local social enterprise called Community Cleaning Services (CCS) (Thieme 2015). With the help of my early contacts as referrals, I contacted the "lead entrepreneur" of each cleaning team asking whether I could work with them for a day. Borrowed uniform and gumboots in my rucksack, I caught an early matatu aiming to get to the meeting grounds before $7 \mathrm{am}$, when the team convened to start the cleaning rounds. I would typically spend a whole morning as another cleaner amongst the team, taking orders from the sonko (boss) as we navigated from one public toilet facility to the next. I spent the first few months shadowing different cleaning teams before requesting any interviews, and initially never pulled out my notepad or recorder, perhaps also in part as a stubborn response to many cleaners' taunting question on the first day, "where is your camera?". This embodied participant observation got me closer to the business dealings of these youth, and granted me literal and figurative access to private domestic and social spaces usually inaccessible to visitors (especially wazungu). It also exposed me to the critical infrastructural conditions of Mathare, including water shortages, poor sewage systems and the lack of formally allocated garbage dumping sites.

In the beginning, I would only ask one question every so often and work in silence the rest of the time, listening to the banter and keeping mental notes of each toilet structure, recording the smells, noting the amounts of water used for each job, and trying my best to work fast and not get in the way. With time, the moments spent walking from one job to the next afforded valuable and opportune windows of conversation, where the more technical question related to CCS would veer into broader topics, shifting from the serious to the banal, discussing childhood in mtaani ("the ghetto"), post-election violence, issues concerning tribal relations, what and where was "home", what shoes were in fashion on the second-hand market, and what was a "good Friday night". In turn, I was asked about my daughter, my favourite football team, why I was 
vegetarian and did that even include $k u k u$ (chicken) and again and again about why I was doing this "utafiti (research) thing”, and how I was getting funded.

Nonchalantly waving my hand over my beans and rice to keep the flies away, feeling sweaty, dirty, tired, and wired with ideas and clutching onto images and recent memories from the day, I quickly realised that the research data that emerged from these casual shared occasions of "breaking bread" or kuzurura (loitering) in between jobs were the most precious. But while I was sitting on a stoop amongst the guys, on certain days as a co-worker rather than a researcher, I was nevertheless acutely aware of my positionality as a European woman from elsewhere observing, cataloguing, interjecting and even amused by the macho banter taking place. These were the times when my license to inquire had been granted, more so than the copy of my Kenyan Research Permit in my bag. It was during these informal interactions that I felt allowed to visibly set my recorder on my knee, and take out my tattered notepad to quickly scribble a few mnemonic notes referring to numbers, expressions or metaphors. With time, my interlocutors become research collaborators, sometimes grabbing the notepad to mark up the page to explain something related to their business that I kept asking about. They would produce graphic illustrations to explain the organisational structure of their business, for example; illustrations that become hugely valuable mental maps reflecting local codes, boundaries and territorial zoning. On other occasions they would grab the recorder or the camera if we were navigating others' territories, such as the municipal dumpsite controlled by different youth gangs. In those instances, it was safer and more feasible for them to be seen with a recording device. All the while, they made fun of my proper Kiswahili and taught me what I really needed to know: street sheng (Swahili slang).

After the first three months of fieldwork, there was a shift, from me calling the guys to ask them if I could come clean with their teams, to the team leaders calling me to either "come for a job" and "show me something" or to have an extra person for a big job. One evening, Moses from the Kibichoi team in Huruma, called me at 10 p.m. to say, "T, thanks for coming today. But you know, I realized I still haven't shown you how to clean the bowl." Out of consideration, protection or lack of trust, most teams, I then realized, asked me to clean the door or walls of the toilet, but never "the bowl". One early morning a few months into the fieldwork, during a homestay with Mambo, I went to clean with the Kawangware team at dawn. It was the first time I met that team's lead entrepreneur. He was tall and muscular and shaven headed, in his late 20's, with a very strong handshake and an intimidating deep voice. His nickname was Jeshi ("soldier"). The sun in Kenya rises around 7 a.m., and it was only $6: 30$ by the time we reached the first job - that infamous toilet that had to be unclogged twice a week. When we arrived, Jeshi took a stick and with force and fervour did the hardest job. Then he turned to me and said, "T, kuja (come). You do the bowl." As I crouched down, with the sun rising in the distance, I tried to hold my breath and swallowed fast and furiously so avoid vomiting from the pungent smell. Then I smirked to myself and thought, either this is a huge compliment or a great way to test "the silly mzungu lady." It was probably a bit of both. 
My time in Mathare became a bizarre combination of ethnographic experiences, including an impromptu head stand competition with a youth gang leader (and street acrobat) in one of the more dangerous parts of Mathare near the River where the illegal brew Shanga is made and violence is known to spark. Staying up on my head that day and beating the other guy turned what had started as a tense confrontation between a Mathare gang leader irritated to see a mzungu on his turf, into an encounter that ended with fist bumps and friendly banter, and an open invitation to come "practice acrobatics on Tuesdays." This would be one of the key moments in the field when my street credibility was earned amongst otherwise hardened young men, as I was then jokingly teased as the girl who could stand on her head all day.

Some of the most valuable moments over the years took place during non-research specific reciprocal exchanges. These included being asked to give the staff of Community Cleaning Services a training session on "how to document" field follow-ups, which gave me insight into how they had been conducting these follow-ups in the first place and what questions they were asking on the ground. It included being asked by one of my key interlocutors to read a short story he had written when a friend of his was killed by police. It included social activist Sammy Gitau letting me spend five hours at his resource center copying down his mental map drawn on the walls of the corrugated metal container, an elaborate chart describing the "government and NGO fund paths" and the "Realities in true colors" of Nairobi, including allegories of inequality with the "lion" elites on the top and the "donkey" survivors of the ghetto at the bottom. Sammy said he was happy for me to document his work because I could give him copies and that would allow him to finally paint over the wall. And it included Huruma Kibichoi Youth Group's leader asking me if I could look over a letter to the local councilor. Their mission was to petition for access to public space for football practice, and their vision was to expand the influence of entrepreneurial youth in local decision-making related to their neighbourhood. Each of these examples reflects key moments of 'data collection' that did not resemble a conventional interview in either form or content, but these were the moments when the 'field' as a space of relationality, knowledge exchange, and ethical responsibility tested the boundaries and norms of ethnographic research.

These seemed to be moments when no one was being asked for information. Instead, knowledge was situated, shared across life-words, and co-produced for a specific end that would ultimately serve different but mutual purposes. These privileged moments as a vulnerable observer (Behar 1996) and vulnerable collaborator were perhaps some of most meaningful, but most challenging to write about. The "carnal sociology" of data collection through apprentice waste work became the vehicle for establishing rapport with research participants in difficult to access social settings (Wacquant 2006). But the politics of representation in the writing output itself made it all the more apparent that both ethnography as data collection and ethnography as text are highly political and laden with power relations that are inextricably linked to the choices we make as ethnographers, and the extent to which we insert ourselves into the life worlds of our interlocutors, a place 
that takes on allegorical and stylized connotations as it comes to be known in our writing and recounting as 'the field' (Nagar 2006; Duneier 2000).

\section{Writing the field}

In his historical account of Kenya's transition to political independence, Lonsdale $(1992,204)$ describes the importance of identifying a usable "political language", one that "unites people over what to argue about". This political language not only "provides the images on which they can base their ideologies", but as researchers it gives us a crucial window into expressions and perceptions of ideas we seek to understand and practices we seek to study. As Atieno-Odhiambo argues, Kenya's post-colonial history has had to be "invented, assembled together, arranged around the metaphor of struggle" (1995, 2). As Atieno-Odhiambo recalls, the "struggle" has been a dominant theme throughout various stages of colonial and post-colonial life, acquiring a politicized status of collective pride especially during Kenyatta's rule, and pertaining to various issues spanning struggles for land, health, housing, water, and the environment (ibid).

On one of the last days of my PhD fieldwork in 2010, I ran into Mike, one of the youth group members in Mathare 10. We exchanged friendly banter and I asked him how life was going. He replied with a smile, “I'm just hustling as always." I joked, "so it's always about the hustle economy?" He paused and nodded. "Yes, exactly. Here in the ghetto it's always about hustle economics." And he hung back his head and laughed. This exchange would later influence the framing of my dissertation and analysis of countless conversations, observational notes, and reflections. In many ways, the hustle became a primary lens through which I saw this work and the constellation of urban struggles and possibilities that co-exist in the everyday city of Nairobi. So here I suggest that the fine line between the realities of the hustle and representations of the hustle is where the entanglements and predicaments of urban ethnography lie.

Since that year of intensive ethnographic fieldwork, my interlocutors' homegrown "political language" has greatly informed the conceptual categories of my ethnographic writing and the ways in which I attempt to narrate the different forms of extreme uncertainty that marks how work, leisure and periods of waiting characterise how youth in a Nairobi slum spend their time and make a living. Beyond accepting the invitation to theorise from the south (Comaroff and Comaroff 2012; Myers 2011), I have tried to theorise from the everyday expressions of my interlocutors who speak of their own urban struggles that span economic, political and inter-personal spheres. Redeploying their everyday vocabularies of 'hustle' and writing about these embedded expressions of Nairobi hustle and the hustle economy more broadly has become a quest to rethink ethnography as both practice and written text. With each returning visit, and often using our modes of social media communication when I have been back in the UK, I have sent my Kenyan friends drafts of my writing, asking them if my interpretations made sense to them. On days when I include their stories in lectures or seminar presentations, I announce the event on facebook messages to let them know. In my 2016 trip, I gave Eliza a copy of the edited volume that included a chapter I had written about her life story. A few 
weeks later, she sent me a text to say she had finally come around to reading the chapter, and she said, 'Thanks $\mathrm{T}$ for nice story. It's a great reference for my life. I may not sit down and really think about my past and progress, but the book makes it easier. Asante sana rafiki (Thank you my friend).'

As a researcher committed to a post-colonial sensibility to ethnographic practice and writing, I am continuously hyper-aware of my own paradoxical positionality, which risks reinforcing unequal power relations that privilege a certain kind of academic knowledge production over that of "ghetto universities" (as youth in Mathare often refer only semi-jokingly to their place of learning). As a post-colonial but nevertheless European researcher committed to writing about African cities, I am conscious not to represent African neighborhoods I study and African lives I write about as "intractable, mute, the abject, or the otherworldly" (Mbembe and Nuttall 2004: 348), as has too often been done in past academic and literary portraitures. So the challenge for urban scholars that are committed to and passionate about doing meaningful ethnographic work in African cities is to provincialise our own academic knowledge and "Northern" heritage while remaining conscious of fully detaching ourselves from our axes of difference and privilege (Nagar 2006). Pieterse's following provocation raises crucial questions about epistemic privilege and who might be equipped to think (let alone write) "from the south": given that the majority of urban dwellers in cities of the global South, particularly in African cities, live in "slums", "is it not time to rethink our epistemic categories and redefine the city through the practices of the slums, and other areas, in order to come to terms with 'the complexity of human nature, and how it wobbles constantly between pragmatism and significance, between pleasure seeking and survival?' (Pieterse 2008, 111; quoting Coates 2003, 43).

This question has animated my work since the beginning of my research in Nairobi, and raised critical reflections on the paradoxical role of urban ethnography as a form of activist politics as well as a politicallyengaged genre of writing. If, as Scheper-Hughes has argued, writing in itself is a form of activism and intervention, our ethnographies carry with them a significant responsibility and demand accountability. Behar's work (1996) during the mid-1990's marked a particular "reflexive turn" in ethnographic scholarship and has been extensively debated amongst anthropologists and cultural geographers alike. But beyond the critical reflection on the unequal power relations related to our own positionalities as ethnographers studying lives on the margins, the commitment to "giving a voice" to our research participants is simultaneously an imperative but also a potential problem of "tyranny" (Cooke and Kothari 2001). Therefore, engaging with "vulnerable ethnography" may be a way to address this inherent tension: let what is observed or heard "influence the course of the observed events", while recognizing that the ways in which ethnographers coproduce knowledge with their interlocutors and write their voices into the ethnographic text is always contingent. As Duneier (2000) notes in his postscript of Sidewalk, reflecting on the fragility and ambiguity of trust between an ethnographer and research participants, "we may feel trusted and accepted by colleagues and 'friends,' but full acceptance is difficult to measure by objective standards and a rarity in any case" (Duneier 2000: 338). The vulnerability of the ethnographer, therefore, traverses the doing and the writing of 
ethnography, as we grapple with the predicaments and implications of getting close to our interlocutors, all the while hyper-aware that trust is fragile, and acceptance impossible to measure.

It has also become increasingly clear to me that over the years, my interest in learning about hustle and the lives of those who self-identify as 'hustlers' has turned me into a sort of hustler (Venkatesh 2008). But perhaps it is the continuous struggle of both the field work and the labour of writing, reaching for the asymptote of cultural interpretation, that makes ethnography meaningful in its unfinished and aspirational enterprise. That is also what drives the 'going back', and the need to follow the questions that emerge from the last trip's encounters and field-notes. At the same time, the temporal, spatial and virtual relationship between 'going back' and 'staying connected' through various forms of social media is a relatively recent dynamic that has rapidly shifted conceptions of where and when the 'field' appears, how we engage with our interlocutors, both in person and digitally, and how they, in turn, engage with our writing. ${ }^{2}$

\section{Conclusion}

It seems timely to dedicate a paper (and indeed a special feature) not only to post-colonial interrogations of representation concerning African cities and the 'urban south' of these cities in particular, but also to the methodological dilemmas that bridge ethnographic practice and writing. Mbembe and Nuttall have argued that the "failure of contemporary scholarship to describe the novelty and originality" of Africa is in part due to the fact that "the way in which societies compose and invent themselves in the present (the creativity of practice) is always ahead of the knowledge produced about them" (Mbembe and Nuttall 2004: 348). Therefore, the conceptual categories that provide familiar theoretical hooks on which empirical observations about a place might be latched are not only insufficient, they become reductionist, and typically euro-centric in their orientation and normative stance. Given that cities in the global South have been in recent decades experiencing an unprecedented rate and scale of urban growth outpacing formal employment, planning and service provisions (Satterthwaite 2007; UN-Habitat 2008; Saunders 2010; Myers 2005), African cities in particular are constantly "inventing themselves in the present" (Mbembe and Nuttall 2004) in a continuous and iterative process of daily bricolage (Levi Strauss 1966), tinkering, assembling, reworking, fixing, repurposing, as work is made rather than found at every turn.

Aiming to research and write about hustle economies in a way that offers an "alternative vision" (Myers 2011) of African urbanism raises questions of representation and story-telling. This paper has turned inside out some of the intimate vacillations of my on-going urban ethnographic journey in Nairobi. The discussion

\footnotetext{
${ }^{2}$ An extensive elaboration on the ethical and methodological questions raised by new digital methods goes beyond the scope of this paper but merit further investigation and will increasingly become an important topic for ethnographers combining 'in person' ethnographies with 'digital presence' in the field. For more on this, see the work of the Digital Humanities Network at the University of Cambridge: http://www.digitalhumanities.cam.ac.uk/
} 
dialogued with post-colonial and feminist scholarship seeking to reflect on the knowledge politics of fieldwork, drawing on a reflexive analysis of how "the production of ethnographic knowledge is shaped by the shifting contextual, and relational contours of the researcher's social identity with respect to her subjects, and by her social situatedness or positionality in terms of gender, race, class, sexuality and other axes of social difference" (Nagar and Geiger 2000: 2). Various urban ethnographers have grappled with these questions, particularly when their scholarship is entangled with a political commitment to social justice issues inextricably linked to the social fields they study, or when a researcher's position as an 'academic-activist' compels them to intervene in the field in some way (Lancione 2016b; Duneier 2000; Scheper-Hughes 2009). This self-reflexivity, as Nagar suggests, is valuable but too often omits more vexing questions including 'who we are writing for', which means that one's own practice of humility within the field is not sufficient if our own written outputs are relegated to academic audiences alone, and the words of our interlocutors only become nice quotes interwoven in our academic theoretical prose.

The continuous self-critical reflection involved in ethnography re-animates a question posed by Geertz (1988) almost 30 years ago: how is it that ethnographers transfigure observations of other people (marginalized insofar as their stories are under-documented or misrepresented) into such persuasive rhetoric that those people are imaginable primarily through texts and their authors? Here Geertz reserves his harshest criticism for ethnographic writing that takes on an autobiographical stance in the pursuit we call fieldwork. He insists it is inappropriate to interiorize too much "what is in fact an intensely public activity". Here I return to Behar's (1996) suggestion that whilst we may start to 'go public' with our research, we continue our labour through continuous introspection. The question therefore is to what extent our own deliberations and intimate vacillations have a place in our 'public' writing, and how clearly we should articulate our own stance in the matters of marginality we study, and to what extent we should allow ourselves to imagine, together with our research interlocutors turned friends and collaborators, 'alternative visions' and future scenarios. Perhaps only then will we know the extent to which our work as ethnographers has effects beyond the ivory tower.

Author:

Tatiana A. Thieme is a Lecturer in Human Geography at UCL. Email: t.thieme@ucl.ac.uk

Address:

Dr. Tatiana A. Thieme

Department of Geography

University College London (UCL)

26 Bedford Way, London.WC1H 0AH.

\section{REFERENCES}

Amin, A., and N. Thrift. 2016. Seeing Like a City. London: Polity Press. 
Atieno-Odhiambo, E.S. 1995. "The Invention of Kenya" in Decolonialization and Independence in Kenya: 1940-1993, Ogot, B. A., and W. R. Ochieng, eds., pp. 1-24, EAEP: Nairobi.

Behar, R. 1996. The Vulnerable Observer. Boston: Beacon Press.

Bernard. R. H. 2006. Research Methods in Anthropology: qualitative and quantitative approaches. Fourth edition. AltaMira Press.

Clifford, J. 1986. "Partial Truths", In J. Clifford, and G. E. Marcus, eds., Writing Culture: The Poetics and Politics of Ethnography, 1-26. Berkeley: Los Angeles and London: University of California Press.

Cooper, E., and D. Pattern, eds. 2015. Ethnographies of Uncertainty. London: Palgrave MacMillan.

Comaroff, J. and J. Comaroff 2012. Theory from the South: Or, How Euro-America Is Evolving Toward Africa. Boulder: Paradigm Publishers.

Crang, M., and I. Cook. 2007. Doing Ethnographies. London: Sage.

Cooke B. and U. Kothari 2001, Participation: The New Tyranny? London: Zed Books.

Duneire, M. 2000. Sidewalk. New York: Farrar, Straus and Giroux.

Ference M. 2016. 'Together We Can': Redefining the Meaning of Work in Kenya's Informal Transportation Sector. Anthropology of Work Review, 37(2).

Ferguson, J. 2006. Global Shadows: Africa in the neoliberal world order. Duke: Duke University Press.

Geertz, C. 1988. Works and Lives: The Anthropologist as Author. Stanford: Stanford University Press.

Geertz, C. 1973. The Interpretations of Cultures. New York: Basic Books.

Jeffrey C and Dyson J 2009. Telling Young Lives: Portraits of Global Youth. Philadelphia: Temple University Press.

Lancione, M., ed. 2016a. Rethinking Life at the Margins. The Assemblage of Contexts, Subjects, and Politics. London: Routledge.

Lancione, M. 2016b, The ethnographic novel as activist mode of existence: Translating the field with homeless people and beyond, Social \& Cultural Geography, 1-22. doi:10.1080/14649365.2016.1231336.

Lonsdale, John 1992. "The Conquest State of Kenya 1895-1905”, in Unhappy Valley: Conflict in Kenya and Africa, edited by Bruce Berman and John Lonsdale, 11-44, James Currey: London.

Mbembe, A., and S. Nuttall. 2004. Johannesburg: The Elusive Metropolis. Durham: Duke University Press. McFarlane, C. 2010. "The Comparative City: Knowledge, Learning, Urbanism." International Journal of Urban and Regional Research 34: 725-742. 
McKensie, L. 2015. Getting by: Estates, class and culture in austerity Britain. Bristol: The Policy Press.

Myers, G. 2011. African Cities: Alternative Visions of Urban Theory and Practice. London: Zed.

Nagar, R., \& Geiger, S. 2007. "Reflexivity, Positionality and Identity in Feminist Fieldwork Revisited". In A. Tickell, E. Sheppard, J. Peck, \& T. Barnes (Eds.), Politics and Practice in Economic Geography. (pp. 267-278). London: Sage.

Nagar, R. 2002. "Footloose Researchers, 'Traveling Theories' and Transnational Feminist Praxis." Gender, Place and Culture 9(2): 179-186.

Pieterse, E. 2008. City Futures: Confronting the Crisis of Urban Development. London: Zed.

Pieterse, E. 2013. "Grasping the Unknowable: Coming to Grips with African Urbanisms." In E. Pieterse and A. Simone, eds., Rogue Urbanism. Emergent African Cities, 19-35. Auckland Park, South Africa: Jacana Media.

Pieterse, E. and A. Simone, eds. 2013. Rogue Urbanism: Emerging African Cities. Auckland Park: Jacana Media.

Sangtin Writers and R. Nagar, 2006. Playing with Fire. Feminist Thought and Activism through Seven Lives in India. Minneapolis: University of Minnesota Press.

Satterthwaite, David 2007. "The Transition to a Predominantly Urban World and its Underpinnings", Human Settlements Discussion Paper, IIED: London.

UN-HABITAT 2008. The State of the World's Cities 2010/2011: Bridging the Urban Divide, Earthscan: London.

Scheper-Hughes, N. 2009. “Making anthropology public.” Anthropology Today 25 (4): 1-3.

Scheper-Hughes, N. 1995. "The Primacy of the Ethical: Propositions for a Militant Anthropology", Current Anthropology, 36, 3,409-440

Simone, A. 2004. "People as Infrastructure: Intersecting Fragments in Johannesburg." Public Culture 16 (3): $407-429$.

Simone, A. 2009. City Life from Jakarta to Dakar: Movements at the Crossroads. New York: Routledge.

Thieme, T. 2010. "Youth, Waste and Work in Mathare: Whose Business and Whose Politics?" Environment and Urbanization, 22(2), pp. 333-352.

Thieme, T. 2013. The 'Hustle' amongst Youth Entrepreneurs in Mathare's Informal Waste Economy, Journal of Eastern African Studies, 7(3): 389-412. 
Thieme, T. 2015. "Turning hustlers into entrepreneurs, and social needs into market demands: corporatecommunity encounters in Nairobi, Kenya", Geoforum, 59, 228-239.

Thieme, T. 2017. "The Hustle Economy: Informality, Uncertainty, and Geographies of Getting By", Progress in Human Geography, DOI: 10.1177/0309132517690039.

Vasudevan, A. 2014. "The Makeshift City: Towards a Global Geography of Squatting”, Progress in Geography. DOI: 10.1177/0309132514531471.

Venkatesh, S. 2008. Gang Leader for a Day. London: Penguin Books.

Wacquant, L. 2006. Body and Soul: Notebooks of an apprentice boxer. Oxford: Oxford University Press.

Weru, J. 2004. "Community Federations and City Upgrading: The Work of Pamoja Trust and Muungano in Kenya”, Environment and Urbanization 16(1): 47-62. 